\title{
Genomic signatures of local directional selection in a high gene flow marine organism; the Atlantic cod (Gadus morhua) Einar E Nielsen* ${ }^{* 1}$, Jakob Hemmer-Hansen ${ }^{\dagger 1}$, Nina A Poulsen ${ }^{1,2}$, Volker Loeschcke ${ }^{2}$, Thomas Moen ${ }^{3}$, Torild Johansen ${ }^{4}$, Christian Mittelholzer ${ }^{5,8}$, Geir-Lasse Taranger ${ }^{4}$, Rob Ogden ${ }^{6}$ and Gary R Carvalho ${ }^{7}$
}

\begin{abstract}
Address: ${ }^{1}$ National Institute of Aquatic Resources, Technical University of Denmark, Vejlsøvej 39, DK-8600 Silkeborg, Denmark, ${ }^{2}$ Department of Biological Sciences, Genetics and Ecology, University of Aarhus, Building 1540, Ny Munkegade, DK-8000 Aarhus C, Denmark, ${ }^{3}$ CIGENE, PO Box 5003, N-1434 Ås, Norway, ${ }^{4}$ Institute of Marine Research Tromsø, PO Box 6404, N-9294 Tromsø, Norway, 5 Institute of Marine Research, PO Box 1870, Nordnes N-5817 Bergen, Norway, ${ }^{6}$ Tepnel Research Products and Services, Appleton Place, Livingston, EH54 7EZ, UK, 7 Molecular Ecology \& Fisheries Genetics Laboratory, School of Biological Sciences, Environment Centre Wales, Bangor University, Bangor, Gwynedd LL57 2 UW, UK and ${ }^{8}$ Current address: University of Basel, Klingelbergstrasse 50/70, CH-4056 Basel, Switzerland

Email: Einar E Nielsen* - een@aqua.dtu.dk; Jakob Hemmer-Hansen - jhh@aqua.dtu.dk; Nina A Poulsen - nap@aqua.dtu.dk; Volker Loeschcke - volker.loeschcke@biology.au.dk; Thomas Moen - thomas.moen@umb.no; Torild Johansen - torild.johansen@imr.no; Christian Mittelholzer - christian.mittelholzer@unibas.ch; Geir-Lasse Taranger - geir.lasse.taranger@imr.no; Rob Ogden - rogden@tepnel.co.uk; Gary R Carvalho - g.r.carvalho@bangor.ac.uk

* Corresponding author †Equal contributors
\end{abstract}

Published: I December 2009

BMC Evolutionary Biology 2009, 9:276 doi:10.1 186/147/-2/48-9-276

This article is available from: http://www.biomedcentral.com/I47I-2 |48/9/276

(c) 2009 Nielsen et al; licensee BioMed Central Ltd.

This is an Open Access article distributed under the terms of the Creative Commons Attribution License (http://creativecommons.org/licenses/by/2.0), which permits unrestricted use, distribution, and reproduction in any medium, provided the original work is properly cited.

\begin{abstract}
Background: Marine fishes have been shown to display low levels of genetic structuring and associated high levels of gene flow, suggesting shallow evolutionary trajectories and, possibly, limited or lacking adaptive divergence among local populations. We investigated variation in 98 gene-associated single nucleotide polymorphisms (SNPs) for evidence of selection in local populations of Atlantic cod (Gadus morhua L.) across the species distribution.

Results: Our global genome scan analysis identified eight outlier gene loci with very high statistical support, likely to be subject to directional selection in local demes, or closely linked to loci under selection. Likewise, on a regional south/ north transect of central and eastern Atlantic populations, seven loci displayed strongly elevated levels of genetic differentiation. Selection patterns among populations appeared to be relatively widespread and complex, i.e. outlier loci were generally not only associated with one of a few divergent local populations. Even on a limited geographical scale between the proximate North Sea and Baltic Sea populations four loci displayed evidence of adaptive evolution. Temporal genome scan analysis applied to DNA from archived otoliths from a Faeroese population demonstrated stability of the intra-population variation over 24 years. An exploratory landscape genetic analysis was used to elucidate potential effects of the most likely environmental factors responsible for the signatures of local adaptation. We found that genetic variation at several of the outlier loci was better correlated with temperature and/or salinity conditions at spawning grounds at spawning time than with geographic distance per se.
\end{abstract}

Conclusion: These findings illustrate that adaptive population divergence may indeed be prevalent despite seemingly high levels of gene flow, as found in most marine fishes. Thus, results have important implications for our understanding of the interplay of evolutionary forces in general, and for the conservation of marine biodiversity under rapidly increasing evolutionary pressure from climate and fisheries induced changes in local environments. 


\section{Background}

When genotype by environment interactions take place, populations can evolve traits that confer a Darwinian fitness advantage in their local habitat. The process and the resulting patterns are termed "local adaptation" [1]. For adaptive divergence of populations to take place, the evolutionary force of directional selection should be stronger than random genetic drift and the homogenising effect of migration among populations [2]. Accordingly, local adaptations are expected to be rare or absent in species with extensive gene flow, such as many marine fishes [3]. Even though some groups of marine fishes, such as coral reef fishes, have been found to be highly genetically structured [4], more than 40 years of population genetic research has typically demonstrated low levels of genetic differentiation among local demes compared to other fish species and terrestrial organisms [5].

It is notoriously difficult to separate genetic from environmental effects when traits of presumed adaptive value are measured directly in the wild [6]. Furthermore, disentangling genetic from environmental effects on phenotypes is a challenge in relatively large aquatic organisms such as many marine fish species, where experimental designs such as common garden and reciprocal transplantation require large facilities. Alternatively, genome scan approaches using a high number of genetic markers in natural populations can provide a powerful shortcut for demonstrating local selection pressures by allowing the identification of outlier loci with divergent levels of genetic differentiation $[7,8]$. In particular, targeted approaches investigating gene-associated rather than random DNA marker variation holds great promise [9]. Targeted genome scans have recently been used in natural populations of various organisms such as trees (white spruce) [10] and fish (sticklebacks) [11].

The Atlantic cod (Gadus morhua L.) has been the subject of numerous population genetic studies and thus represents one of the best studied marine fish species within the field. Population genetic studies have demonstrated low, albeit significant genetic differentiation on various hierarchical levels, ranging from clear transatlantic differences [12-14] to microgeographical population structure of demes separated by a few tens of kilometres [15-17]. At the same time there is growing evidence that commonly observed variation in life history traits among putative natural populations of Atlantic cod is at least partly determined by genetic rather than environmental differences, see [18] and references therein. Earlier studies have indicated that functional genes may be under selection in natural populations of Atlantic cod. Already in the 1960's the classical studies of haemoglobin polymorphisms in cod by Sick [19] identified a locus ( $H b I)$ most likely under environmental selection. Recently, Andersen et al. [20] identified the molecular basis as well as the different oxygen binding properties of the haemoglobin alleles, thereby providing the important link between genotypes and phenotypes of adaptive importance. Another example is the identification of the Pantophysin (Pan I) locus in cod [21] which has been shown to display markedly elevated levels of genetic differentiation compared to presumed neutral markers, patterns which are potentially driven by temperature selection $[22,23]$. A more extensive survey of genes was recently conducted by Moen et al. [24], who reported on the first genome scan approach in the species. They assessed variation in 318 Single nucleotide polymorphisms (SNPs) in a selection of samples from two cod populations (northeast Arctic and Norwegian coastal cod) and identified a number of outlier loci as candidates for being under adaptive evolution. However, in summation, these studies have focused on single genes and/or a restricted geographical area not using random population samples. Consequently, even though Atlantic cod represents one of the most frequently targeted marine species in population genetic research, the genomic architecture as well as the geographical scale and distribution of adaptive divergence in this and other high gene flow marine fishes is still relatively poorly known (see also review by Nielsen et al. [25]).

In this study, we tested the hypothesis that populations of Atlantic cod are adapted to local environmental conditions and therefore display genomic signatures of divergent selection. We applied genome scan methods to identify outlier loci potentially associated with adaptive population divergence on global, regional and local scales as well as an explorative landscape genetic analysis focusing on environmental factors suspected to be involved in local adaptation.

\section{Results}

\section{Genome scan approach}

First, we scanned for global outlier loci by including a selection of major population groups from the western Atlantic (Canada), Greenland, Iceland, northeast Arctic cod, Norwegian coastal cod, North Sea, English Channel and the Baltic Sea (see Table 1 and Figure 1). Eight gene associated SNP loci displayed statistically significant patterns of divergent genetic differentiation consistent with a model of directional selection at the associated gene or other closely linked genes (Figure 2a). Bayes factors for global outliers were high, with seven loci having $\log 10$ values above 2 (decisive) and four of these had a $\log 10$ Bayes factor of 5, which corresponds to a posterior probability of one. The outliers displayed large differences in allele frequencies among major cod populations (Figure 1 ). There was no clear trend that particularly divergent allele frequencies (or pairwise $\mathrm{F}_{\mathrm{ST}}$ values, see additional file 1) for outlier loci were associated with one or two spe- 
Table I: Atlantic cod samples analysed in the present study.

\begin{tabular}{|c|c|c|c|c|}
\hline geographical locality & position & $\begin{array}{l}\text { sampling year } \\
\text { (abbreviation) }\end{array}$ & sample size & peak spawning \\
\hline Baltic Sea 1,3 & $54.51^{\circ} \mathrm{N} 15.28^{\circ} \mathrm{E}$ & 1996 (BAS) & 40 & June \\
\hline Arkona Basin ${ }^{3}$ & $54.53^{\circ} \mathrm{N} 13.33^{\circ} \mathrm{E}$ & 1996 (ARK) & 40 & May \\
\hline Western Baltic Sea ${ }^{3}$ & $54.56^{\circ} \mathrm{N} 12.28^{\circ} \mathrm{E}$ & 2007 (WBA) & 36 & March \\
\hline Belt Sea ${ }^{3}$ & $55.11^{\circ} \mathrm{N} 10.28^{\circ} \mathrm{E}$ & 1996 (BES) & 40 & March \\
\hline Kattegat $^{3}$ & $57.15^{\circ} \mathrm{N} 11.35^{\circ} \mathrm{E}$ & 1996 (KAT) & 40 & April \\
\hline Central North Sea ${ }^{1,2,3}$ & $55.17^{\circ} \mathrm{N} 03.39^{\circ} \mathrm{E}$ & 1996 (CNS) & 40 & April \\
\hline Southern North Sea ${ }^{2}$ & $54.29^{\circ} \mathrm{N} 0.02^{\circ} \mathrm{E}$ & 2006 (SNS) & 40 & April \\
\hline English Channel ${ }^{1,2}$ & $50.47^{\circ} \mathrm{N} 0.29^{\circ} \mathrm{E}$ & $2005(\mathrm{ECH})$ & 40 & February \\
\hline Northern North Sea ${ }^{2}$ & $58.00^{\circ} \mathrm{N} 03.00^{\circ} \mathrm{W}$ & 2003 (NNS) & 40 & April \\
\hline Northeast Arctic cod, Lofoten ${ }^{1,2}$ & $68.35^{\circ} \mathrm{N} 12.13^{\circ} \mathrm{E}$ & 2003 (NEAC) & 40 & April \\
\hline Norwegian coastal cod, Lofoten 1,2 & $68.12^{\circ} \mathrm{N} 14.44^{\circ} \mathrm{E}$ & 2003 (NCC) & 40 & April \\
\hline Faeroe Plateau ${ }^{2}$ & $62.53^{\circ} \mathrm{N} 06.18^{\circ} \mathrm{W}$ & 2002 (FPL) & 40 & March \\
\hline Faeroe Bank ${ }^{4}$ & Unknown & 1978 (FBA78) & 32 & March \\
\hline Faeroe Bank $k^{2,4}$ & $60.56^{\circ} \mathrm{N} 08.52^{\circ} \mathrm{W}$ & 2002 (FBA) & 40 & March \\
\hline Iceland South ${ }^{1,2}$ & $63.49^{\circ} \mathrm{N} 21.05^{\circ} \mathrm{W}$ & 2002 (ICS) & 40 & April \\
\hline Iceland North² & $66.17^{\circ} \mathrm{N} 15.45^{\circ} \mathrm{W}$ & 2002 (ICN) & 40 & April \\
\hline Greenland ${ }^{1,2}$ & $66.35^{\circ} \mathrm{N} 53.32^{\circ} \mathrm{W}$ & 2005 (GRE) & 40 & April \\
\hline Western Atlantic (Canada)! & $47.39^{\circ} \mathrm{N} 55.24^{\circ} \mathrm{W}$ & 1998 (CAN) & 40 & May \\
\hline
\end{tabular}

I) Samples included in global analysis, 2) samples in south-north transect, 3) samples in North Sea-Baltic Sea transect, 4) samples in temporal comparison.

cific populations except for Hsp 90 (Baltic) and Gmo0588_0274 (western Atlantic). The candidate loci identified from a wide geographical ascertainment sample in this study (see Methods section) did not show any general trend of decreased or inflated levels of genetic differentiation (Figure 2) compared to the loci identified in a single population ascertainment sample by Moen et al [24]. To investigate patterns of selection on a regional scale, we scanned eastern and central Atlantic populations in a south-north transect using samples from the English Channel, southern North Sea, central North Sea, northern North Sea, Faeroe Bank, Faeroe Plateau, Norwegian coastal cod, northeast Arctic cod, Iceland south, Iceland north and Greenland. At this geographical level, seven outlier loci were identified (Figure 2b), all with Bayes factor values well above $2(\log 10)$. The loci identified as likely subjects of directional selection were identical to the loci identified on a global scale, except for the locus Gmo0588_0274, which was not an outlier at this geographical scale. Likewise, divergent allele frequencies (Figure 1) at this locus were only found for the western Atlantic sample (CAN). When leaving out the northeast Arctic cod sample, which generally appeared most genetically divergent, five of the seven outlier loci still remained highly significant (results not shown). Thus, also on this geographical scale, outliers were generally not associated with any particular population. On a local scale, we scanned the geographical proximate but environmentally distant [26] North Sea and the Baltic Sea populations including samples from the transition area. Four outliers, of which three had $\log 10$ Bayes factors above 2, signalled evidence of directional selection at this small geographical scale (Figure 2c). Two of the four loci identified here were not identified as outliers on larger geographical scales. Accordingly, the spatial genome scan approach identified overall ten loci where a model of selection was much more likely than a neutral model. A temporal analysis of the Faeroe Bank population using DNA from historical otolith samples collected in 1978 and contemporary tissue samples showed no evidence of directional (or stabilising) selection over time (Figure 2d). Loci identified as likely subjects to directional selection through the spatial analyses (Figure 2a-c) did generally not display patterns of elevated levels of genetic differentiation over time (Figure 2d), which is consistent with temporal stability of spatial directional selection patterns. A significantly higher proportion of the candidate loci (5 of 15) compared to random loci ( 5 of 83 ) were identified as outliers (chi-square, $\mathrm{P}<0.01$, see also additional file 2 ).

\section{Landscape genetics}

The MDS plot (Figure 3) based on all 88 "neutral" loci (all loci except the ten outliers) showed a clear isolation of the western Atlantic sample from Canada (CAN). In addition, the Baltic Sea samples (BAS and ARK) were separated from the remaining central and eastern Atlantic samples (see also additional file 1). The landscape genetic analysis of the global outlier loci revealed that seven of eight loci were significantly associated with temperature on spawning grounds at spawning time (Table 2). Five loci were associated with salinity, while four loci were associated with each of the geographic variables latitude and longitude. In addition, the landscape genetic method also identified associations with environmental variables for loci 

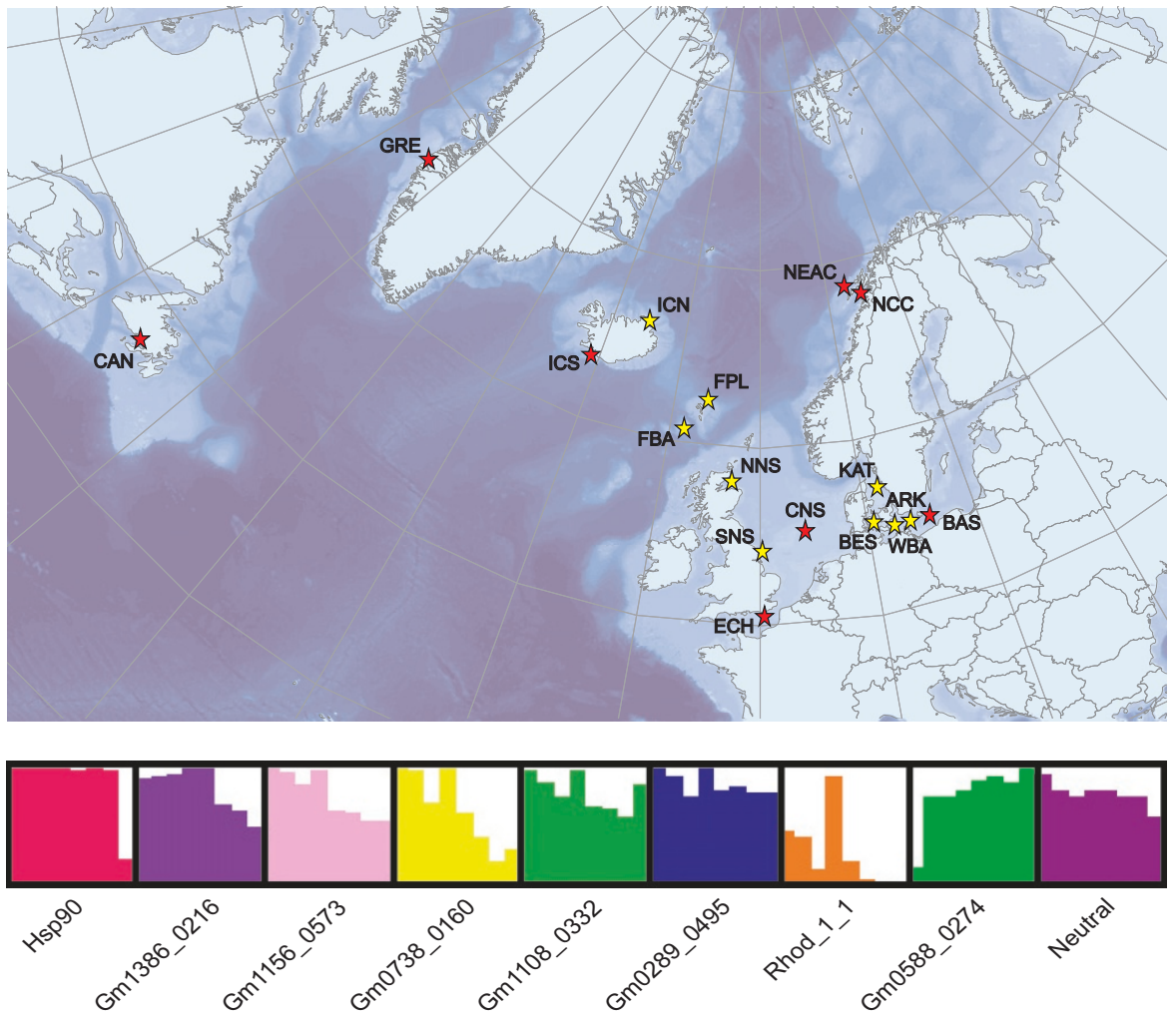

\section{Figure I}

Map of sampling locations. Samples were collected from the western Atlantic (CAN), Greenland (GRE), northern Iceland (ICN), southern Iceland (ICS), the Faeroe Bank (FBA), the Faeroe Plateau (FPL), Norwegian coastal cod (NCC), Northeast Arctic cod (NEAC), northern North Sea (NNS), the English Channel (ECH), southern North Sea (SNS), central North Sea (CNS), Kattegat (KAT), Belt Sea (BES), western Baltic Sea (WBA), Arkona Basin (ARK) and the central Baltic Sea (BAS). Red stars indicate samples used in the global analyses, while yellow stars mark additional samples used in regional comparisons (see also Table I). A bar chart shows allele frequencies in each of the eight samples used in the global analyses. Presented are global outlier loci identified by BAYESCAN along with a representative neutral locus, displaying a global $\mathrm{F}_{\mathrm{ST}}$ corresponding to the global neutral $F_{S T}$ (eight outlier loci removed, see Figure 2a)). Populations from left to right for each locus are CAN, GRE, ICS, NEAC, NCC, CNS, ECH, BAS.

which had not been identified as outliers using the genome scan method (see additional file 3).

\section{Discussion}

This study suggests that loci subject to directional selection can be found on various geographical scales in Atlantic cod. In addition, the results suggest that a large number of loci could be subject to directional selection on a genomic scale among local populations. Local directional selection appears to be general and relatively widespread and can be found on a number of geographical scales since the global or regional outliers identified are not exclusively dependent on one or a few particularly divergent cod populations. Furthermore, although it is difficult to completely disentangle the effects of geographic and environmental distance, a higher proportion of the identified outlier loci were associated with environmental parameters on spawning grounds than with geographic variables. This suggests, but does not establish, these environmental factors as potentially responsible for adaptive divergence among cod populations.

The remaining "neutral" SNP markers generally exhibited very low levels of genetic differentiation and, accordingly, limited resolution of patterns of population relationships, except for the highly divergent western Atlantic and Baltic Sea cod populations. This is somewhat in contrast with evidence from microsatellite markers (e.g. see $[12,14,27])$, showing higher levels of differentiation but also high variance among loci. Although great care should be taken when comparing levels of genetic structure between markers with different mutational properties $[28,29]$, this difference may suggest that estimates of genetic differentiation from a limited number of micros- 
a)

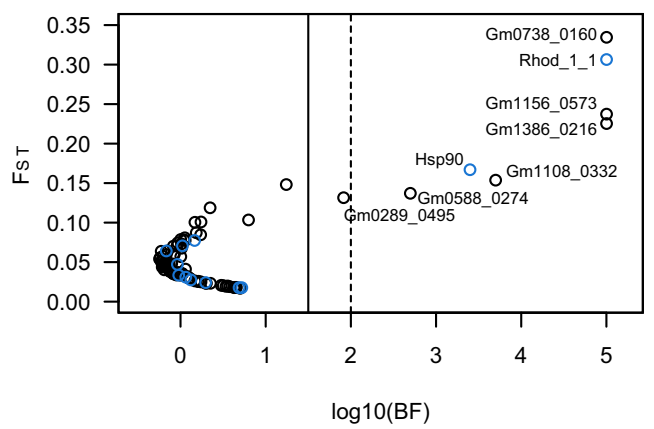

c)

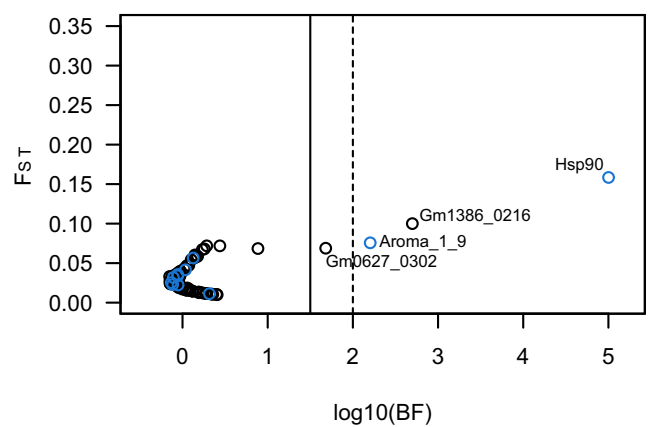

b)

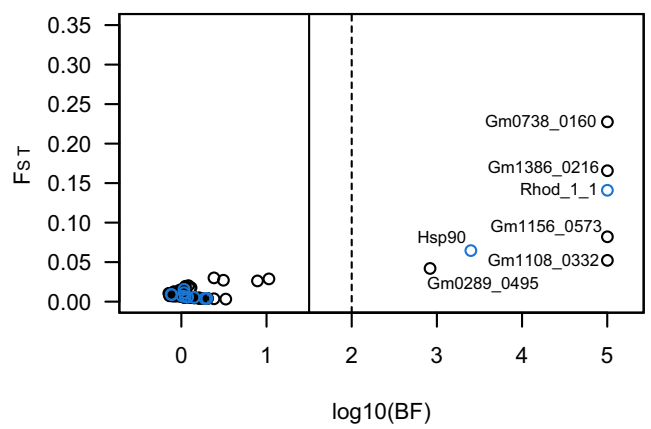

d)

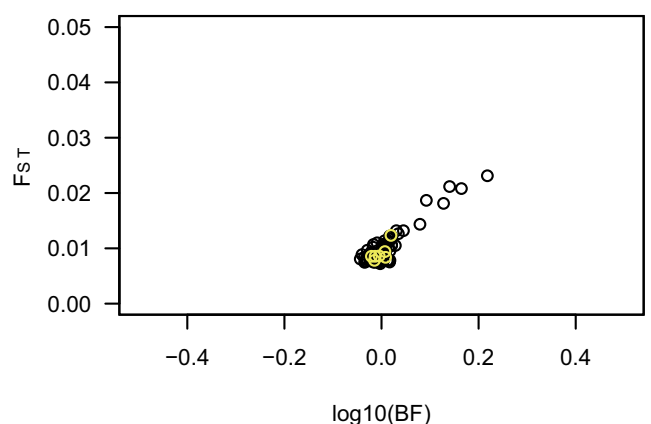

\section{Figure 2}

Spatial and temporal scans for identification of $F_{S T}$ outlier loci potentially subject to differential selection. a) Global dataset with eight samples, b) South-north transect in the Atlantic, c) North Sea - Baltic Sea transect and d) Temporal samples from the Faeroe Bank (note different scale on secondary axis). Shown are Log transformed Bayes factors and locus specific $\mathrm{F}_{\mathrm{ST}}$ from BAYESCAN. Vertical lines mark Log IO(BF) of I.5 (solid) and 2 (broken) corresponding to posterior probabilities of locus effects of 0.97 and 0.99 , respectively. Loci with a posterior probability of I were ascribed a Log I0(BF) of 5. Novel SNPs from this study, which were ascertained in a different set of individuals than used for the random set of markers, are labelled blue in a), b) and c). Loci identified as outliers in the global data set are labelled yellow in d). Monomorphic loci were removed in each simulation.

Table 2: Significant associations between candidate loci for local adaptation and environmental variables.

\begin{tabular}{lcccc}
\hline & latitude & longitude & temperature & salinity \\
\hline Rhod_I_I & $* * *$ & $* * *$ & $* * *$ & $*$ \\
Gm0738_0160 & $* * *$ & $* * *$ & $* * *$ & $* *$ \\
GmII56_0573 & & $* * *$ & $* * *$ & $* *$ \\
GmI386_0216 & $* * *$ & & $* * *$ & $* * *$ \\
Gm0588_0274 & $* * *$ & $* * *$ & $* * *$ & \\
Hsp90 & & & $* * *$ \\
Gm0289_0495 & & & $* *$ & \\
\hline
\end{tabular}

Only global $\mathrm{F}_{\mathrm{ST}}$ outliers identified by BAYESCAN are shown (see additional file 3 for more loci and environmental variables in an extended analysis). *** refers to $\mathrm{P}<0.001$, ** to $\mathrm{P}<0.01$ and $*$ to $\mathrm{P}<$ 0.05 after Bonferroni correction. Hsp90 = Heat shock protein 90, Rhod_I_I = Rhodopsin. atellite loci may be even more inflated by hitch-hiking selection than previously assumed. Alternatively, levels of SNP differentiation may be depressed due to the presence of SNPs, which are monomorphic in a number of population samples. This in turn may also explain why we find no evidence for balancing selection in cod. Simulations have shown that scenarios with low levels of population structure provide very low power for detecting loci under balancing selection [30].

The apparent high number of loci with strong statistical support for selection may be somewhat unexpected given the very low level of neutral genetic differentiation among cod populations. However, neutral divergence has in general been shown to be a poor predictor of adaptive trait variation [31]. The proportion of loci subject to selection resembles the findings using genome scan methods for highly structured Atlantic salmon (Salmo salar) popula- 


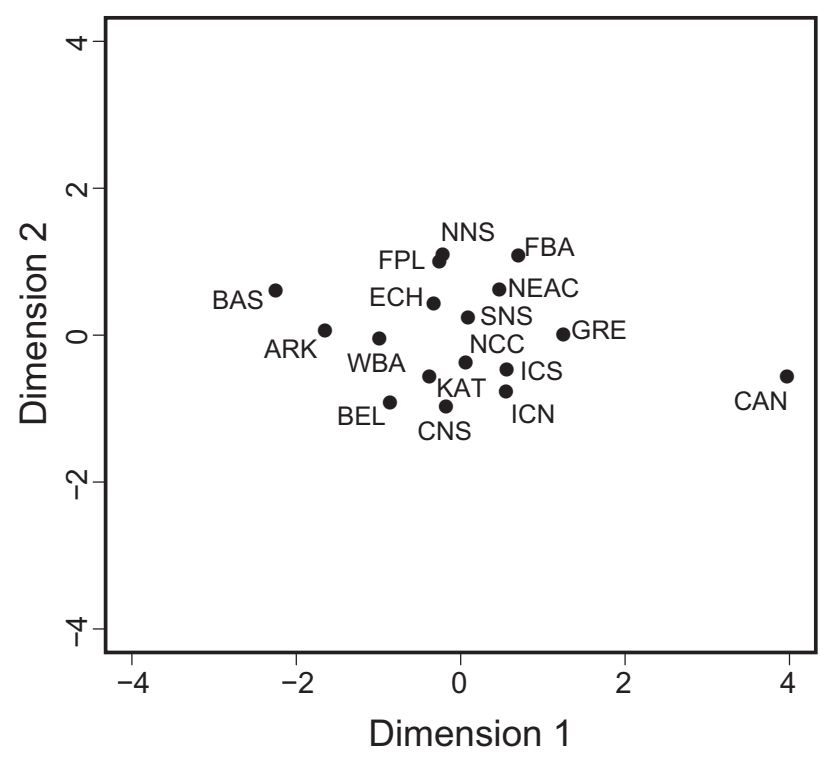

Figure 3

Multi dimensional scaling plot of "neutral" $F_{\text {ST }}$ estimates between all spatial samples. $F_{S T}$ estimates are based on all loci, except ten loci identified as potentially under selection (see Figure 2).

tions [32]. The result that the North Sea/Baltic Sea cod population comparison only yielded four outliers likely to be subject to directional selection may be surprising given the unique low saline, low oxygen environment for cod in the Baltic Sea. However, although adaptations in Baltic Sea cod may be essential, they may be distributed over few genes, also considering the relatively short history of the Baltic Sea [26]. Alternatively, we cannot exclude that ascertainment bias might have affected results of analyses including Baltic Sea samples (see also below). More detailed studies of the genetic architecture of adaptive traits in Baltic Sea cod are warranted to elucidate these issues. It should be stressed, however, that results from this study should not be taken as a direct estimate of the proportion of genes under divergent (and balancing) selection in different cod populations. Ascertainment bias [33] could potentially have affected the geographical distribution of outliers, since the majority of loci were ascertained from EST libraries consisting of only Norwegian coastal cod [24] and the candidate loci originate from a different and wider ascertainment sample. This could potentially result in higher variability, different levels of genetic differentiation and a different frequency of outliers for comparisons including Norwegian coastal cod and/or our candidate loci. However, marine fishes have been shown to display relatively shallow genetic structure compared to other organisms including other fish species [5], suggesting that ascertain- ment bias may be less of a problem here [34]. This theoretical consideration is supported by the fact that estimates of heterozygosity and proportion of monomorphic loci were not markedly different in the sample of Norwegian coastal cod (see additional file 2) compared to samples from other populations, except for the most differentiated populations of Canadian cod and Baltic Sea cod. This phenomenon of shared polymorphisms could be caused by the fact that Norwegian coastal cod is closely related to the ancestral population of cod [35] and therefore serve as a superior ascertainment sample (see [36] for an example for Drosophila). Furthermore, overall genetic differentiation of "neutral" loci for the EST derived loci and our own candidate loci was almost identical (illustrated in Figure 2), suggesting limited systematic difference between loci from the two ascertainment panels. In conclusion, we only think that ascertainment bias is likely to have significantly reduced the identified number of loci under selection for the very divergent Canadian cod. However, even if the proportion of outliers in the most divergent populations within the remaining cluster (i.e. northeast Arctic cod and Baltic Sea cod) might be mildly underestimated, we expect ascertainment bias to play a relatively minor role on regional and local scales based on theoretical expectations and our own evaluation of data.

Another potential concern in relation to establishing outliers as products of directional selection is the high number of loci tested (98). With an alpha level of 0.05 we would expect five significant outliers, which in fact is not so far from the present results. However, the statistical support for individual outliers identified here is generally much stronger. We should expect only one outlier by chance with a Bayes factors above $2(\log 10)$, but the computed values are almost exclusively above $2(\log 10)$, which is generally interpreted as "decisive". Four loci have $\log 10$ values as high as 5 , which was the value ascribed to posterior probabilities of 1 (Bayes factor is infinity). Accordingly, we are still convinced that the majority of these outliers are affected by directional selection and not just outliers by chance. We think that our evidence for selection is as strong as possibly achievable given the statistical method and the number of loci at hand.

As evidenced above, the identified outlier genes originate both from randomly chosen gene associated SNPs and from specifically targeted SNPs in candidate genes of known functions. Interestingly, a relatively high proportion of candidate genes showed evidence of being subject to selection compared to the randomly chosen SNPs (app. $30 \%$ versus app. $6 \%$ ). The identified outlier genes code for proteins with highly divergent functions (additional file 4 ), suggesting that directional selection for local adaptations in cod occur along multiple environmental dimensions. For example, heat-shock protein genes, represented 
by $H s p 90$, have been shown to be involved in various stress responses in fish including temperature, salinity and pollution [37]. Aromatase plays a regulatory role in sex determination, gametogenesis, central nervous system development and sex behaviour [38] and rhodopsin is a pigment gene involved in the formation of photoreceptor cells and the perception of light [39]. Alternatively, since temperature is important for proper functioning of all proteins and physiological processes $[40,41]$ temperature differences among geographical locations alone could be driving the evolutionary response for all genes in concert. The landscape genetic analysis partly supports this hypothesis, since almost all outlier loci appear to have alleles significantly associated with temperature. However, salinity also emerges as a likely driver of directional selection for local adaptation in Atlantic cod. Both temperature and salinity have been associated with phenotypic variation in cod. For instance, body shape variation was observed among juvenile cod originating from different Canadian spawning populations when reared under different temperature conditions [42]. Likewise, adaptive trait variation in response to salinity has been strongly suggested for cod in the Baltic Sea, showing divergent egg buoyancy and sperm mobility [43]. Still, the landscape genetic analysis should only be considered explorative. We have investigated a small subset of environmental factors potentially affecting allele frequencies at outliers. Likewise, most parameters are correlated to some extent, leading to significant associations with both geography and environment. This is illustrated by the positive correlations with environment for a number of genes not identified as outliers. It is not a simple task to unambiguously establish the link between genomic signatures of local adaptation and specific environmental conditions, particularly if only correlation analyses are applied. More research is needed on cod reared under controlled conditions in order to establish the genetic architecture of traits subject to local directional selection leading to fitness difference between native and non-native fish [2].

\section{Conclusion}

Previously, genetic evidence of local adaptation at the DNA level in marine fishes has been inferred from single genes $[20,44,45]$, or from restricted geographical areas [24]. To our knowledge, the present targeted genome scan approach represents the first attempt to elucidate genomic signatures of directional selection in natural populations of a marine fish on various geographical scales across its range. Even though our understanding of the genetic architecture of adaptive evolution in marine fishes is not as advanced as in other well studied fish species (e.g. sticklebacks [46] or whitefish [47]), our findings strongly suggest that marine fishes are not only isolated into local populations, even on relatively small geographical scales [4]. Despite being connected by variable levels of gene flow, these populations can indeed follow semi-independent adaptive evolutionary trajectories shaped by selection by their local environments. Thus, adaptive population divergence seems to be possible and may even be prevalent despite seemingly high levels of gene flow often found in marine fishes. Our findings have implications for sustainable management of marine fishes by underpinning the local population as the focal management unit. Thus, we cannot rely on immigration to rehabilitate declining populations, since non-native individuals will have lower fitness and therefore are less likely to be successful in their new environment. Moreover, the extirpation of local populations may represent irreversible changes to the gene pool and associated adaptive evolutionary potential [48]. Recent assertions of global warming causing recruitment failure in cold-adapted North Sea cod emphasize the importance of maintaining the adaptive potential of exploited species [49]. Likewise, predictions on future distribution and abundance of marine fishes should not rely on simplified spatial models viewing whole species as single units with global bioclimatic niches. In order to improve the predictive power of future responses to environmental change, information on the dynamics of locally adapted populations, as well as on population-specific adaptive trait values, will be required.

\section{Methods \\ Sampling}

In total 708 adult individuals were analysed from 17 spatial samples and one temporal sample, all consisting of approximately 40 individuals (Table 1 and Figure 1). Spatial analyses were conducted using samples from three different hierarchical levels; global (CAN, GRE, ICS, NCC, NEAC, ECH, CNS and BAS), a regional south-north transect of central and north-eastern Atlantic population samples (ECH, SNC, CNS, NNS, FBA, FPL, NCC NEAC, ICS, ICN and GRE) and a North Sea - Baltic Sea transect (CNS, KAT, BES, WBA, ARK and BAS). The temporal comparison was conducted on samples from the Faeroe Bank in the eastern Atlantic (FBA78 and FBA).

\section{DNA analysis}

DNA was extracted from tissue or archived otoliths (FBA78) using the proteinase K/chelex method [50]. Overall 98 SNPs were genotyped by the MassARRAY system from SEQUENOM. Eighty-six SNPs were selected from previously published EST derived SNPs from cDNA libraries of Norwegian coastal cod (ascertainment sample) [24]. Of these, eighty were randomly selected, while six were specifically selected because they were expected to play a role in local adaptation. In addition, we analysed twelve novel SNPs developed for this study (Table 3 and additional file 5). These SNPs were discovered by screening genomic DNA with primers designed from public teleostei or Atlantic cod sequences. Individuals for the initial 
Table 3: Novel SNPs analysed in this study

\begin{tabular}{|c|c|c|c|}
\hline locus name & protein & snp location & genbank accession no. \\
\hline Aroma_I_9 & Aromatase & Intronic & DQ402370 \\
\hline Aroma_2_3 & Aromatase & Exonic & $\overline{\mathrm{DQ} 402370}$ \\
\hline FshB_I_I & Follicle stimulating hormone & Exonic & $\overline{\mathrm{DQ} 402373}$ \\
\hline Gh_l_l & Growth hormone & Intronic & $\overline{E U 676171}$ \\
\hline Haemoglobin_alpha & Haemoglobin alpha subunit & Intronic & F]666966 \\
\hline Haemoglobin_beta & Haemoglobin beta subunit & Intronic & Fl666984 \\
\hline Hsp90 & Heat shock protein 90 & Intronic & GU063866 \\
\hline LDHB\#I & Lactate Dehydrogenase B & Intronic & A) 609233 \\
\hline Rhod_I_I & Rhodopsin & Exonic & AF385832 \\
\hline S2_I_I & Ribosomal protein S2 & Intronic & AY292468 \\
\hline S2_I_6 & Ribosomal protein S2 & Intronic & AY292468 \\
\hline Gm_snpl & Unknown & Unknown & GU063867 \\
\hline
\end{tabular}

GenBank accession numbers refer to reference sequences for each locus. See additional file 5 for detailed information on individual SNPs.

screen (ascertainment sample) were chosen in order to cover the major part of the distributional area of Atlantic cod (CAN, NEAC, CNS and BAS). Thus, among the total of 98 SNPs, fifteen were from candidate genes for adaptive evolution, with functions primarily related to temperature stress, growth and reproduction (see additional file 2).

\section{Statistical analysis}

Observed and expected levels of heterozygosity and tests for conformance to Hardy-Weinberg Equilibrium following [51] were calculated for each locus and population in ARLEQUIN ver. 3.1 [52]. Summary statistics for each locus are presented in additional file 2. Overall and locusspecific $\mathrm{F}_{\mathrm{ST}}$ values were estimated by Weir and Cockerham's $\theta$ [53] in GENEPOP 4.0.10 [54]. Pairwise single locus $\mathrm{F}_{\mathrm{ST}}$ between samples used in the global analyses were estimated for each of the loci identified as outliers in BAYESCAN. In addition, pairwise multi-locus $\mathrm{F}_{\mathrm{ST}}$ were estimated for all loci, excluding the outlier loci (see additional file 1). Likewise, multi-locus "neutral" pairwise $\mathrm{F}_{\mathrm{ST}}$ were estimated between all samples and used to generate a MDS plot (Figure 3) using the program Vista 5.6.3. [55].

To detect signatures of natural selection we used the Bayesian likelihood method implemented via reversible jump Markov Chain Monte Carlo in BAYESCAN [30]. The Bayesian regression approach implemented in BAYESCAN has several advantages over the widely used approach based on summary statistics implemented in FDIST2 [56]. Firstly, in BAYESCAN $\mathrm{F}_{\mathrm{ST}}$ is modelled using a logistic regression model implementing a locus effect and a population effect, while simulations in FDIST2 are based on an Island Model. Thus, BAYESCAN allow population specific $\mathrm{F}_{\mathrm{ST}}$ in contrast to the symmetrical Island Model in FDIST2, and therefore BAYESCAN should be appropriate for Atlantic cod, which is expected to display non-sym- metrical patterns of gene flow among natural populations. Secondly, and supporting this theoretical reasoning, analyses of simulated data have shown that the Bayesian regression approach performs slightly better than FDIST2 when scenarios deviate from the standard Island Model [56,57]. Thirdly, FDIST2 simulates a distribution of $\mathrm{F}_{\mathrm{ST}}$ from the empirical estimate, which is itself influenced by loci potentially under selection. This problem can be alleviated by iteratively removing outlier loci before running the programme $[30,56]$. However, this approach is subject to a certain degree of subjectivity, which is avoided in the Bayesian approach in BAYESCAN. BAYESCAN directly estimates the posterior probability that a locus is under selection (see below) in contrast to an earlier method build on the same basic regression model, which provided an approximated p-value [57]. In short, BAYESCAN estimates the probability that a locus is under selection by calculating a Bayes factor, which is simply the ratio of the posterior probabilities of two models (selection/neutral) given the data. A Bayes factor between 32 and $100(\log 10=1.5-2)$ is "very strong evidence" of different statistical support for the two models and corresponds to a posterior probability between $0.97-0.99$. For Bayes factors above $100(\log 10>2)$ the evidence is interpreted as "decisive" and correspond to posterior probabilities between 0.99 and 1 .

In BAYESCAN, monomorphic loci were removed from each run. Following 10 pilot runs of 5000 iterations and an additional burn-in of 50000 iterations, we used 100000 iterations (sample size of 5000 and thinning interval of 20) to identify loci under selection from locus specific Bayes factors. A Bayes factor of infinity, corresponding to a posterior probability of 1 , was assigned a $\log 10$ value of 5 . In order to alleviate potential problems arising from allele frequency correlations between sam- 
ples $[58,59]$, we ran a global analysis with eight representative samples covering the distributional area of the species rather than including all available samples. In addition, we ran regional analyses with more samples from restricted geographical areas.

A spatial analysis, using the program SAM [60], was performed in order to identify associations between alleles and environmental variables. Two environmental parameters, temperature and salinity, as well as latitude and longitude were assessed (see below). We chose to use temperature and salinity at spawning time (but see also additional file 3 for analyses applying a wider set of closely related environmental variables) since this is as close as possible to the most critical time of the cod lifecycle, i.e. when the life stages (i.e. egg and larvae) have little option for actively avoiding unfavourable conditions (see also discussion in [61]). Since the early life stages of Atlantic cod are pelagic, we would expect a relatively strong correlation between surface/near surface data and the actual environmental conditions experienced by these life stages at most sampling locations. Temperature data were obtained from NOAAs Optimal Interpolation version 2 monthly SST analyses (OI.v2 monthly Sea Surface Temperature, available from the IRI/LDEO Climate Data Library at http://ingrid.ldgo.columbia.edu). Salinity data were collected from NOAAs Global Ocean Data Assimilation System (GODAS monthly below sea level salinity at a depth of $5 \mathrm{~m}$, http://ingrid.ldgo.columbia.edu) and from the oceanographic database managed by the International Council for the Exploration of the Sea (ICES surface salinity data, available from http://www.ices.dk). Environmental data were integrated in a Geographic Information System (ArcGIS 9 from ESRI) in order to extract data covering a latitude/longitude grid of $0.5^{\circ}$ ${ }^{*} 0.5^{\circ}$ to $1^{\circ} * 1^{\circ}$ around each sample position. Environmental variables used in SAM were means of a sampling period from 1990 to 2007. The null hypothesis of no association between an allele and an environmental variable was rejected if the examined variable explained the observed allelic distribution better than a model with a constant only. We changed the critical P value from 0.05 to 0.01 and 0.001 for the implemented Wald test to demonstrate robustness of significant associations. Since only two alleles were present at each locus, leaving only one independent variable, we present the results as associations between locus and environmental variable.

\section{Authors' contributions}

EN conceived and designed the study and drafted the manuscript. JH-H analysed the majority of the data, participated in the design of the study as well as drafting and commenting on the manuscript. NAP participated in the design of the study, data analysis and commented on previous drafts of the manuscript. VL participated in the design of the study and commented on manuscript drafts. TM, TJ, CM, G-LT and RO provided data and commented on manuscript drafts. GC participated in the design of the study and in drafting and commenting of the manuscript. All authors have read and approved the final version of the manuscript.

\section{Additional material}

\section{Additional file 1}

Pairwise $F_{S T}$. Pairwise Fst for eight samples used in the global analysis (See Figure 1 and Table 1). Shown are single locus estimates for each of the ten loci identified as candidates for adaptive evolution (see Figure 2) and multi-locus estimates based on all loci, excluding the ten outliers. Click here for file

[http://www.biomedcentral.com/content/supplementary/14712148-9-276-S1.DOC]

\section{Additional file 2}

Summary statistics. Observed and expected levels of heterozygosity and tests for conformance to Hardy-Weinberg Equilibrium per locus and sample.

Click here for file

[http://www.biomedcentral.com/content/supplementary/14712148-9-276-S2.XLS]

\section{Additional file 3}

Results from extended spatial analyses. All loci identified by SAM [60] to be significantly associated with one or more of nine variables (seven environmental variables, latitude and longitude) in global and regional analyses.

Click here for file

[http://www.biomedcentral.com/content/supplementary/14712148-9-276-S3.DOC]

\section{Additional file 4}

Putative physiological function of outlier loci. Blast hits for outlier loci were obtained by blasting contig sequences from [24] or own sequences (see Table 3 for reference sequences in GenBank) against the nucleotide database at GenBank. Biological processes and molecular functions were identified in the Gene Ontology database (http://www.geneontology.org, [62]). Where available, gene ontology is reported for Danio rerio $\left({ }^{a}\right)$, otherwise Homo sapiens ( $(b)$ is used as reference.

Click here for file

[http://www.biomedcentral.com/content/supplementary/14712148-9-276-S4.DOC]

\section{Additional file 5}

Novel SNPs analysed in this study. New SNPs analysed in this study with PCR primers to amplify a fragment containing the SNP. Click here for file [http://www.biomedcentral.com/content/supplementary/14712148-9-276-S5.XLS]

\section{Acknowledgements}

The authors thank the participants in the European Union networks and projects, "Marine Genomics Europe" (Grant number: GOCE-CT-2004505403) "Seafood Plus" (Grant number: 506359) and "FinE" (Grant number: 044276) for input and fruitful discussions. We are grateful to Eydfinn Mag- 
nussen and Christophe Pampoulie for providing samples and to Thomas Damm Als for help with graphics.

\section{References}

I. Williams GC: Adaptation and Natural Selection Princeton University Press, Princeton; 1966.

2. Kawecki TJ, Ebert D: Conceptual issues in local adaptation. Ecol Lett 2004, 7:1225-I24I.

3. Conover DO, Clarke LM, Munch SB, Wagner GN: Spatial and temporal scales of adaptive divergence in marine fishes and the implications for conservation. I Fish Biol 2006, 6:2 I-47.

4. Palumbi SR, Warner RR: Why gobies are like hobbits. Science 2003, 299:5I-52.

5. Waples RS: Separating the wheat from the chaff: patterns of genetic differentiation in high gene flow species. J Hered 1998, 89:439-450

6. Endler JA: Natural selection in the wild Princeton University Press, Princeton; 1986.

7. Beaumont MA: Adaptation and speciation: what can F-st tell us? Trends Ecol Evol 2005, 20:435-440.

8. Storz JF: Using genome scans of DNA polymorphism to infer adaptive population divergence. Mol Ecol 2005, | 4:67| -688.

9. Bonin A: Population genomics: a new generation of genome scans to bridge the gap with functional genomics. Mol Ecol 2008, I 7:3583-3584.

10. Namroud MC, Beaulieu J, Juge N, Laroche J, Bousquet J: Scanning the genome for gene single nucleotide polymorphisms involved in adaptive population differentiation in white spruce. Mol Ecol 2008, I 7:3599-36I3.

II. Mäkinen HS, Cano JM, Merilä J: Identifying footprints of directional and balancing selection in marine and freshwater three-spined stickleback (Gasterosteus aculeatus) populations. Mol Ecol 2008, I 7:3565-3582.

12. Bentzen P, Taggart CT, Ruzzante DE, Cook D: Microsatellite polymorphism and the population structure of Atlantic cod (Gadus morhua) in the northwest Atlantic. Can J Fish Aquat Sci |996, 53:2706-272।.

13. Arnason E: Mitochondrial cytochrome b DNA variation in the high-fecundity Atlantic cod: Trans-atlantic clines and shallow gene genealogy. Genetics 2004, 166:1871-1885.

14. Nielsen EE, Hansen MM, Meldrup D: Evidence of microsatellite hitch-hiking selection in Atlantic cod (Gadus morhua L.): Implications for inferring population structure in non-model organisms. Mol Ecol 2006, I 5:3219-3229.

15. Ruzzante DE, Taggart CT, Cook DA: Nuclear DNA basis for shelf- and bank scale population structure in northwest Atlantic cod (Gadus morhua): Labrador to George Bank. Mol Ecol 1998, 7:1663-1680.

16. Knutsen H, Jorde PE, André C, Stenseth NC: Fine-scaled geographical population structuring in highly mobile marine species: the Atlantic cod. Mol Ecol 2003, I 2:385-394.

17. Nielsen EE, Wright PJ, Hemmer-Hansen J, Poulsen NA, Gibb IM, Meldrup D: Population structure of cod (Gadus morhua L.) in the North Sea and west of Scotland; the role of sampling loci and individuals for inferring micro-geographical differentiation. Mar Ecol Prog Ser 2008, 276:2 1 3-225.

18. Hutchings JA, Fraser DJ: The nature of fisheries- and farminginduced evolution. Mol Ecol 2008, I 7:294-3 I3.

19. Sick K: Haemoglobin polymorphism of cod in the Baltic and the Danish Belt Sea. Hereditas 1965, 54:49-73.

20. Andersen $\varnothing$, Wetten OF, De Rosa MC, André C, Alinovi CC, Colafranceschi M, Brix O, Colosimo A: Haemoglobin polymorphisms affect the oxygen-binding properties in Atlantic cod populations. Proc R Soc Lond B Bio 2009, 276:833-84I.

21. Pogson GH: Nucleotide polymorphism and natural selection at the pantophysin (Pan I) locus in the Atlantic cod, Gadus morhua (L.). Genetics 200 I, I 57:317-330.

22. Case RAJ, Hutchinson WF, Hauser L, Van Oosterhout C, Carvalho GR: Macro- and micro-geographic variation in pantophysin (Pan I) allele frequencies in NE Atlantic cod Gadus morhua . Mar Ecol Prog Ser 2005, 30 I:267-278.

23. Pampoulie C, Ruzzante DE, Chosson V, Jorundsdottir TD, Taylor L Thorsteinsson V, Danielsdottir AK, Marteinsdottir G: The genetic structure of Atlantic cod (Gadus morhua) around Iceland: insight from microsatellites, the Pan I locus, and tagging experiments. Can J Fish Aquat Sci 2006, 63:2660-2674.

24. Moen T, Hayes B, Nilsen F, Delghandi M, Fjalestad KT, Fevolden SE, Berg PR, Lien S: Identification and characterisation of novel SNP markers in Atlantic cod: Evidence for directional selection. BMC Genet 2008, 9:18.

25. Nielsen EE, Hemmer-Hansen J, Larsen PF, Bekkevold D: Population genomics of marine fishes: identifying adaptive variation in space and time. Mol Ecol 2009, I 8:3 I 28-3I50.

26. Johannesson $\mathrm{K}$, André $\mathrm{C}$ : Life on the margin: genetic isolation and diversity loss in a peripheral marine ecosystem, the Baltic Sea. Mol Ecol 2006, 15:2013-2029.

27. O'Leary DB, Coughlan J, Dillane E, McCarthy TV, Cross TF: Microsatellite variation in cod Gadus morhua throughout its geographic range. J Fish Biol 2007, 70:310-335.

28. Hedrick PW: A standardized genetic differentiation measure. Evolution 2005, 59: 1633-1638.

29. Jost L: $\mathbf{G ( S T )}$ and its relatives do not measure differentiation. Mol Ecol 2008, I 7:40I 5-4026.

30. Foll $M$, Gaggiotti $O$ : A Genome-scan method to identify selected loci appropriate for both dominant and codominant markers: A Bayesian perspective. Genetics 2008, I 80:977-993.

31. Leinonen T, O'hara RB, Cano JM, Merila J: Comparative studies of quantitative trait and neutral marker divergence: a metaanalysis. J Evolution Biol 2008, 2 I: I-I7.

32. Vasemägi $A$, Nilsson J, Primmer CR: Expressed sequence taglinked microsatellites as a source of gene-associated polymorphisms for detecting signatures of divergent selection in Atlantic salmon (Salmo salar L.). Mol Biol Evol 2005 22:1067-1076.

33. Clark AG, Hubisz MJ, Bustamante CD, Williamson $\mathrm{SH}$, Nielsen $\mathrm{R}$ : Ascertainment bias in studies of human genome-wide polymorphism. Genome Res 2005, I5:|496-I502.

34. Rosenblum EB, Novembre J: Ascertainment bias in spatially structured populations: A case study in the eastern fence lizard. J Hered 2007, 98:33I-336.

35. Bigg GR, Cunningham CW, Ottersen G, Pogson GH, Wadley MR Williamson P: Ice-age survival of Atlantic cod: agreement between palaeoecology models and genetics. Proc $R$ Soc B-Biol Sci 2008, 275:163-173.

36. Schlötterer C, Harr B: Single nucleotide polymorphisms derived from ancestral populations show no evidence for biased diversity estimates in Drosophila melanogaster. Mol Ecol 2002, I I:947-950.

37. Basu N, Todgham AE, Ackerman PA, Bibeau MR, Nakano K, Schulte PM, Iwama GK: Heat shock protein genes and their functional significance in fish. Gene 2002, 295:173-183.

38. Piferer $\mathrm{F}$, Blázquez $\mathrm{M}$ : Aromatase distribution and regulation in fish. Fish Physiol Biochem 2005, 3 I:2 15-226.

39. Nickle $B$, Robinson PR: The opsins of the vertebrate retina; insights from structural, biochemical and evolutionary studies. Cell Mol Life Sci 2007, 64:2917-2932.

40. Pörtner $\mathrm{HO}$, Knust R: Climate change affects marine fishes through the oxygen limitation of thermal tolerance. Science 2007, 3 I 5:95-97.

4I. Pörtner HO, Bock C, Knust R, Lannig G, Lucassen M, Mark FC, Sartoris FJ: Cod and climate in a latitudinal cline: physiological analyses of climate effects in marine fishes. Climate research 2008, 37:253-270.

42. Marcil J, Swain DP, Hutchings JA: Genetic and environmental components of phenotypic variation in body shape among populations of Atlantic cod (Gadus morhua). Biol J Linn Soc 2006, 88:35I-365.

43. Nissling A, Kryvi $\mathrm{H}$, Vallin L: Variation in egg buoyancy of Baltic cod Gadus morhua and its implications for egg survival in prevailing conditions in the Baltic Sea. Mar Ecol-Prog Ser 1994, I 1 0:67-74.

44. Schulte PM, Glémet HC, Fiebig AA, Powers DA: Adaptive variation in lactate dehydrogenase-B gene expression: Role of a stress-responsive regulatory element. P Natl Acad Sci USA 2000 , 97:6597-6602.

45. Hemmer-Hansen J, Nielsen EE, Frydenberg J, Loeschcke V: Adaptive divergence in a high gene flow environment: Hsc70 variation in the European flounder (Platichthys flesus L.). Heredity 2007, 99:592-600. 
46. Colosimo PF, Peichel CL, Nereng K, Blackman BK, Shapiro MD, Schluter D, Kingsley DM: The genetic architecture of parallel armor plate reduction in threespine sticklebacks. PloS Biol 2004, 2:635-64I.

47. Rogers SM, Bernatchez L: The genetic architecture of ecological speciation and the association with signatures of selection in natural lake whitefish (Coregonas sp Salmonidae) species pairs. Mol Biol Evol 2007, 24:|423-I438.

48. Árnason $\mathrm{E}$, Hernandez UB, Kristinsson K: Intense habitat-specific fisheries-induced selection at the molecular Pan I locus predicts imminent collapse of a major cod fishery. PLOS ONE 2009, 4:e5529.

49. O'Brien CM, Fox CJ, Planque B, Casey J: Climate variability and North Sea cod. Nature 2000, 404: I42.

50. Estoup A, Largiader CR, Perrot E, Chourrout D: Rapid one-tube DNA extraction for reliable PCR detection of fish polymorphic markers and transgenes. Mol Mar Biol Biotech 1996, 5:295-298.

5I. Guo S, Thompson E: Performing the exact test of Hardy-Weinberg proportion for multiple alleles. Biometrics 1992 48:36|-372.

52. Excoffier L, Laval G, Schneider S: Arlequin ver. 3.0: An integrated software package for population genetics data analysis. Evol Bioinform Online 2005, I:47-50.

53. Weir BS, Cockerham CC: Estimating F-statistics for the analysis of population structure. Evolution $\mid 984,38: 1358-1370$.

54. Raymond M, Rousset F: GENEPOP (version I.2): population genetics software for exact tests and ecumenicism. J Hered 1995, 86:248-249.

55. Young FW: ViSta: the visual statistics system 2nd edition. Research Memorandum 94-I (b). L.L. Thursone Psychometric Laboratory, University of North Carolina, Chaper Hill, NC; 1996.

56. Beaumont MA, Nichols RA: Evaluating loci for use in the genetic analysis of population structure. Proc $R$ Soc Lond B Bio 1996 , 263:1619-1626

57. Beaumont MA, Balding DJ: Identifying adaptive genetic divergence among populations from genome scans. Mol Ecol 2004, 13:969-980.

58. Robertson A: Letters to the editor: remarks on the LewontinKrakauer test. Genetics 1975, 80:396.

59. Excoffier L, Hofer T, Foll M: Detecting loci under selection in a hierarchically structured population. Heredity 2009 1 03:285-298.

60. Joost $S$, Kalbermatten $M$, Bonin A: Spatial analysis method (SAM): a software tool combining molecular and environmental data to identify candidate loci for selection. Mol Ecol Res 2008, 8:957-960.

61. Case RAJ, Hutchinson WF, Hauser L, Van Oosterhout C, Carvalho GR: Macro- and micro-geographic variation in pantophysin (Pan I) allele frequencies in NE Atlantic cod Gadus morhua. Mar Ecol-Prog Ser 2005, 30 I:267-278.

62. Ashburner M, Ball CA, Blake JA, Botstein D, Butler H, Cherry JM, Davis AP, Dolinski K, Dwight SS, Eppig JT, Harris MA, Hill DP, IsselTarver L, Kasarskis A, Lewis S, Matese JC, Richardson JE, Ringwald M, Rubin GM, Sherlock G: Gene Ontology: tool for the unification of biology. Nat Genet 2000, 25:25-29.
Publish with Bio Med Central and every scientist can read your work free of charge

"BioMed Central will be the most significant development for disseminating the results of biomedical research in our lifetime. "

Sir Paul Nurse, Cancer Research UK

Your research papers will be:

- available free of charge to the entire biomedical community

- peer reviewed and published immediately upon acceptance

- cited in PubMed and archived on PubMed Central

- yours - you keep the copyright
BioMedcentral 